\title{
Building a Healthy Foundation for the Child from Birth: Need for Collaborative Parenting by the Pediatricians and Pediatric Dentists
}

\author{
Aditi Kapur ${ }^{1}$, Tamchos $\mathrm{R}^{2}$ \\ Journal of Postgraduate Medicine, Education and Research (2022): 10.5005/jp-journals-10028-1553
}

\begin{abstract}
A famous quote rightly says that "The aim of every science is to cause its own extinction." As health care providers, therefore, the fundamental goal of our specialties should be not only to move toward providing the best possible treatment solutions to our patients, but also to reduce the burden of diseases to such an extent, wherever possible, so as to make ourselves less and less relevant to the population we serve.
\end{abstract}

Although preventable, oral diseases like dental caries, are a highly prevalent condition, affecting more than 3.5 billion people worldwide, mainly owing to the lack of preventive care and is closely linked to socioeconomic status and the broader social determinants of health., Early childhood caries (ECC) is defined as any sign of tooth decay in a child less than 6 years of age and has a worldwide pooled prevalence of $48 \%$, which is greater than all known chronic diseases of early childhood, but is usually not considered when describing the overall health status of the child; highlighting the disparity among the other medical and oral conditions. ${ }^{3-5}$

The recommended age for the first dental visit of a child, is at the time of eruption of the first tooth, which is well before the child's first birthday. However, in practice it has been found that the first visit is generally at 6 years of age or beyond, primarily owing to symptomatic conditions, dental caries being the most common. ${ }^{6,7}$ As a result, a greater proportion of unidentified pediatric dental caries remain inaccessible for timely preventive care delivery. Moreover, lack of awareness about the importance of dental health, especially in the deciduous dentition stage, lack of pediatric dental specialists, and un willingness of general dental practitioners to see infants and young children causes a hindrance to the assurance of optimal care.

The identification and addressing of barriers in providing optimum pediatric oral healthcare is important, especially in a developing country like India. These conditions pose a health hazard to children, also increase the burden of untreated cases and dental healthcare expenses. ${ }^{8-10}$ The discrepancies in providing oral healthcare also create a burden on the workforce of general practitioners and pediatricians due to a greater number of emergency cases resulting from dental neglect. Most of these conditions are the ones that could likely be prevented or reduced in its severity with timely preventive advice.

Oral diseases, like several other systemic diseases may be attributed to certain common maladaptive nutritional habits and microbial dysbiosis. ${ }^{11,12}$ The advice for its prevention needs to be centred around certain key factors in a multifactorial etiology, encompassing the general health of a child, genetic influences, environmental influences, diet, microbial load, and conditions
${ }^{1}$ Pedodontics and Preventive Dentistry Oral Health Sciences Center Postgraduate Institute of Medical Education and Research, Chandigarh, India

${ }^{2}$ Pediatric Dentistry Unit, Oral Health Sciences Centre, Postgraduate Institute of Medical Education and Research, Chandigarh, India

Corresponding Author: Aditi Kapur, Pedodontics and Preventive Dentistry Oral Health Sciences Center Postgraduate Institute of Medical Education and Research, Chandigarh, India Phone: +91 9815966348, e-mail: draditikmalhotra@gmail.com

How to cite this article: Kapur A, Tamchos R. Building a Healthy Foundation for the Child from Birth: Need for Collaborative Parenting by the Pediatricians and Pediatric Dentists. J Postgrad Med Edu Res 2022;56(1):1-2.

Source of support: Nil

Conflict of interest: None

affecting tooth morphology. Hence, the knowledge and ability to primarily screen patients who are at risk of developing oral diseases may help in reducing this disease burden. Moreover, knowledge about oral conditions may also help in early detection and greater understanding of certain other medical conditions as well.

The World Health Organization (WHO) identifies the scope for interprofessional practice in the primary healthcare sector. ${ }^{13}$ On an average, children visit a Pediatrician six times in their first year of life and decrease in frequency thereafter. ${ }^{14}$ However, in order to tap into this great potential in ensuring oral health of children, the barriers that need to be bridged include inadequate education and training, time constraints in practice, and lack of referral pathways. ${ }^{15}$

In the present scenario, it is important for Pediatricians to understand the inter-relationships between oral and general health and the basic concepts of common dental diseases to initiate primary treatment and ensure timely referrals to pediatric dentists. WHO endorsed the need for integration of oral healthcare with existing primary care such as child \& maternal health programs, vaccination, general medical check up to raise awareness about ECC, and the importance of breastfeeding and risk factors for dental caries development, particularly addition of free sugars to drinks and food. ${ }^{3}$ Preventive guidance in the first year of life by pediatricians/health care professionals about limitation of sugar intake, avoidance of free sugar in children below one year and brushing twice daily with age appropriate fluoridated tooth paste can go a long way in sensitizing the primary care givers about the importance of oral health in a timely manner. ${ }^{3,16}$ The role 
of pediatricians as primary oral care providers is also indispensable in time-limited emergency care and advise. Since the peak incident of dental trauma in young children is between 2 and 3 years, which is well before they may have had any first contact with a pediatric dentist. Most cases therefore are likely to seek consultation from general dental practitioners or pediatricians, the nature of which can directly affect the outcome in many cases.

Moreover, in the recent years, there has been a major shift in the understanding of pathophysiology of many diseases and the concept of early identification and early treatment is catching on. Maternal oral health has been shown to be closely associated with child's general and oral health, ${ }^{17}$ breast feeding positions/ patterns have been shown to be associated with certain type of malocclusions, ${ }^{18}$ tongue tie at birth is related to many feeding difficulties, GERD ${ }^{19}$ and tooth eruption patterns have shown association with development of autism etc. ${ }^{20}$ Due to change in our understanding and also the growing awareness among parents, this trend of seeking early advice is catching on and therefore, the pediatricians and pediatric dentists need to further strengthen the closer working linkages with an endeavor to offer the best health outcomes for the young growing child patients.

In conclusion, interdisciplinary treatment involving pediatricians and pediatric dentists is an overlooked, but an important aspect in pediatric care as the fundamental aspect of both of these specialties is helping every child to lead a disease-free life where they can develop to their full potential.

\section{References}

1. Benjamin RM. Oral health: the silent epidemic. Public Health Rep 2010;125(2):158-159. DOI: 10.1177/003335491012500202

2. Dye BA. The global burden of oral disease: research and public health significance. J Dent Res 2017;96(4):361-363. DOI: $10.1177 / 0022034517693567$

3. Early Childhood Caries: IAPD Bangkok Declaration. Int J Paediatr Dent 2019;29(3):384-386. DOI: 10.1111/ipd.12490

4. Uribe SE, Innes N, Maldupa I. The global prevalence of early childhood caries: a systematic review with meta-analysis using the WHO diagnostic criteria. Int J Paediatr Dent 2021;31(6):817-830. DOI: $10.1111 /$ ipd.12783

5. U.S. Department of Health and Human Services Oral Health Coordinating Committee. U.S. Department of Health and Human Services Oral Health Strategic Framework, 2014-2017. Public Health Rep 2016;131(2):242-257.
6. American Academy of Pediatric Dentistry. Perinatal and infant oral health care. Pediatr Dent 2018;40(6):216-220.

7. Sanguida A, Vinothini V, Prathima GS, et al. Age and reasons for first dental visit and knowledge and attitude of parents toward dental procedures for Puducherry children aged 0-9 years.J Pharm Bioallied Sci 2019; 11:S413-S419. DOI:10.4103/JPBS.JPBS_54_19

8. Pine CM, Harris RV, Burnside G, et al. An investigation of the relationship between untreated decayed teeth and dental sepsis in 5-year-old children. Br Dent J 2006;200(1):45-47. DOI: 10.1038/ sj.bdj.4813124

9. Sheiham A. Dental caries affects body weight, growth and quality of life in pre-school children. Br Dent J 2006;201(10):625-626. DOI: 10.1038/sj.bdj.4814259

10. Kastenbom L, Falsen A, Larsson P, et al. Costs and health-related quality of life in relation to caries. BMC Oral Health 2019;19(1):187. DOI: 10.1186/s12903-019-0874-6

11. Kilian M, Chapple ILC, Hannig M, et al. The oral microbiome-an update for oral health care professionals. Br Dent J 2016;221(10):657-666. DOI: $10.1038 /$ sj.bdj.2016.865

12. Sheiham A, James WP. Diet and dental caries: the pivotal role of free sugars reemphasized. J Dent Res 2015;94(10):1341-1347. DOI: $10.1177 / 0022034515590377$

13. Varenne B, Makino Y, Petersen PE. Ending childhood dental caries: WHO implementation manual. World Health Organization, $2019.72 \mathrm{~s}$.

14. LeBaron CW, Rodewald L, Humiston S. How much time is spent on well-child care and vaccinations? Arch Pediatr Adolesc Med 1999;153(11):1154-1159. DOI: 10.1001/archpedi.153.11.1154

15. Dickson-Swift V, Kenny A, Gussy M, et al. The knowledge and practice of pediatricians in children's oral health: a scoping review. BMC Oral Health 2020;20:211. DOI: 10.1186/s12903-020-01198-0

16. Kapur A, Thakur JS, Goyal A, et al. Use of fluoridated dentifrices in children: are we in the right direction? Ann Natl Acad Med Sci 2019;55(1):54-59. DOI: 10.1055/s-0039-1694083

17. Dasanayake AP, Gennaro S, Hendricks-Muñoz KD, et al. Maternal periodontal disease, pregnancy, and neonatal outcomes. MCN Am J Matern Child Nurs 2008;33(1):45-49. DOI: 10.1097/01. nmc.0000305657.24613.47

18. Abate A, Cavagnetto D, Fama A, et al. Relationship between breastfeeding and malocclusion: a systematic review of the literature. Nutrients 2020;12(12):3688. DOI: 10.3390/nu12123688

19. American Academy of Pediatric Dentistry. Policy on management of the frenulum in pediatric dental patients. The Reference Manual of Pediatric Dentistry Pediatric Dentistry Chicago, Ill: American Academy of 2021:76-80.

20. Gozes I, Van Dijck A, Hacohen-Kleiman G, et al. Premature primary tooth eruption in cognitive/motor-delayed ADNP-mutated children. Transl Psychiatry 2017;7(2):e1043. DOI: 10.1038/tp.2017.27 